\title{
The promoter of cell growth- and RNA protection-associated SND1 gene is activated by endoplasmic reticulum stress in human hepatoma cells
}

\author{
Sandra Armengol, Enara Arretxe, Leire Enzunza, Sarai Mula, Begoña Ochoa, Yolanda Chico \\ and María José Martínez
}

\begin{abstract}
Background: Staphyloccocal nuclease domain-containing protein 1 (SND1) is involved in the regulation of gene expression and RNA protection. While numerous studies have established that SND1 protein expression is modulated by cellular stresses associated with tumor growth, hypoxia, inflammation, heat-shock and oxidative conditions, little is known about the factors responsible for SND1 expression. Here, we have approached this question by analyzing the transcriptional response of human SND1 gene to pharmacological endoplasmic reticulum (ER) stress in liver cancer cells.

Results: We provide first evidence that SND1 promoter activity is increased in human liver cancer cells upon exposure to thapsigargin or tunicamycin or by ectopic expression of ATF6, a crucial transcription factor in the unfolded protein response triggered by ER stress. Deletion analysis of the 5'-flanking region of SND1 promoter identified maximal activation in fragment $(-934,+221)$, which contains most of the predicted ER stress response elements in proximal promoter. Quantitative real-time PCR revealed a near 3 fold increase in SND1 mRNA expression by either of the stress-inducers; whereas SND1 protein was maximally upregulated (3.4-fold) in cells exposed to tunicamycin, a protein glycosylation inhibitor.
\end{abstract}

Conclusion: Promoter activity of the cell growth- and RNA-protection associated SND1 gene is up-regulated by ER stress in human hepatoma cells.

Keywords: SND1 transcriptional activity, Tudor and nuclease domain containing protein 1, Tudor-SN, ER stress response, ATF6

\section{Background}

The endoplasmic reticulum (ER) mainly functions in proper protein synthesis and maturation, and transport of the correctly folded molecules. When protein folding or export is perturbed and an excess of misfolded client proteins accumulate in the ER lumen (ER stress), eukaryotic cells activate a homeostatic response with a primarily cytoprotective effect, that is collectively termed the unfolded protein response (UPR). The UPR triggers a set of signaling cascades for the control of gene

\footnotetext{
* Correspondence: mariajose.martinez@ehu.es

Department of Physiology, Faculty of Medicine and Dentistry, University of the Basque Country UPV/EHU, Barrio Sarriena s/n, 48940 Leioa, Spain
}

transcription and translation programs, which while emanating from the ER, requires the nucleus and the Golgi apparatus for intracellular signal transduction [1]. In mammals, the principal branches of UPR signaling are mediated by three ER transmembrane stress sensors: PERK (double-stranded RNA-activated protein kinase-like ER kinase), IRE1 (inositol-requiring transmembrane kinase and endonuclease 1) and ATF6 (activating transcription factor 6). Under unstressed condition, these sensors are interacting with the chaperone GRP78 (glucoseregulated protein 78 or $\mathrm{BiP}$ ) repressing the signaling pathways $[2,3]$. Upon ER stress, GRP78 is sequestered by unfolded proteins leading to transient and concerted 
activation of each signaling cascade: PERK-mediated eIF2 $\alpha$ phosphorylation, which mediates general translation attenuation during cellular recovery, PERK-derived ATF4/ ATF3/CHOP pathway, IRE-1-derived XBP1 mRNA splicing and ATF6 activation (recently reviewed in $[4,5]$ ). The three latter pathways induce the expression of distinct but overlapping sets of genes involved in both general and ERspecific proteostasis [3,6-9]. Simultaneously, a subset of cellular mRNAs is translationally silenced by sequestration into discrete cytoplasmic stress granules until stress mitigates or degradation, if ER stress persists [5,10,11].

Staphyloccocal Nuclease Domain containing protein SND1 (also named Tudor-SN, TSN or p100 coactivator) is a multidomain protein that appears to have diverse functions in mammalian cells. Originally described as a transcriptional coactivator essential for normal cell growth [12], SND1 serves multiple functions in biological events spanning from regulation of cell differentiation and proliferation, adipogenesis and biogenesis of lipid droplets to cellular stress responses [13-18]. SND1 has been demonstrated to act as both a nuclease and a ligand. The ample distribution of the protein and its capacity for binding RNA and protein molecules explain the role of SND1 in regulating postranscriptional processes linked to RNA splicing, editing and silencing [18-21]. Accumulating evidence indicates that SND1 plays an important role in RNA protection due to its ability to interact with stress granules protein components and to degrade highly mutated, hyper-edited regions of doublestranded RNAs generated during the cellular stress response [18,22-24]. SND1 also acts as a microRNA (miR) binding protein, having been assigned to bind pre-miR92a in stress granules and interfere with its maturation under hypoxic conditions [25]. The interaction of SND1 with mRNAs and miRNAs may be of notable relevance in cells undergoing a tumor growth-associated stress because of the potential contribution to angiogenesis regulation. So far, the SND1 overexpression that occurs in multiple types of cancer cells has been interpreted to mean parallel activation of the RNA-induced silencing complex activity and degradation of tumor suppressor mRNAs [26-29].

In the particular case of liver cancer, SND1 and NF- $\mathrm{kB}$ intersect at several points. SND1 has been shown to trigger a novel molecular cascade that, mediated by miR-221 and NF- $\mathrm{BB}$ activation, leads to induction of angiogenic factors for hepatocellular carcinoma progression [30]. We demonstrated in human hepatoblastoma model HepG2 cells, that the evolutionary conserved SND1 gene promoter is under Sp1 and NF-Y control in basal conditions and under NF- $\mathrm{kB}$ functional binding in response to TNF $\alpha$-mediated inflammatory stress [31]. SND1 mRNA overexpression was also found in TNF $\alpha$ treated cells [31]. Collectively, these results support the concept that, in liver carcinoma, there is an intertwined relationship between SND1 gene expression and tumour environment inflammation, conditions that are closely linked to ER stress. Here, we seek to extend the previous knowledge of gene transcriptional regulation and have analyzed the transcriptional response of human SND1 gene to pharmacological activation of the UPR in human hepatoma cells. Tunicamycin inhibits protein $\mathrm{N}$-glycosylation [32] and thapsigargin is an inhibitor of the sarco/endoplasmic reticulum $\mathrm{Ca}^{2+}$-ATPase pump that disrupts ER calcium homeostasis [33], and both promote accumulation of misfolded or inadequately processed proteins in the ER lumen and cause ER stress. We present first experimental data indicating that promoter activity and expression of human SND1 gene are activated in cells exposed to thapsigargin or tunicamycin and also following ectopic expression of the transcription factor ATF6. Moreover, we have identified the maximal activation in $\mathrm{SND} / 2$, a promoter region of 934 nucleotides upstream the transcription start site that contains several putative ER stress response elements (ERSE) for the binding of transcription regulators ATF6, ATF and XBP1.

\section{Results and discussion}

\section{ER stress activates SND1 gene promoter activity} and expression

In light of previous reports showing that SND1 participates in a range of stress responses including those associated with cell growth and inflammation, particularly in the liver, and that little is known about the factors controlling SND1 gene expression, we investigated the effect of pharmacologic ER stress on SND1 gene promoter activity in human hepatoblastoma cells. We challenged a human hepatoma cell line, HepG2, with two structurallyunrelated ER stress-inducing drugs, tunicamycin and thapsigargin. Both drugs have proven useful for delineating the molecular grounds of UPR signaling pathways [32-34]. As Fang established [35], we probed $1 \mu \mathrm{M}$ thapsigargin and $5 \mu \mathrm{g} / \mathrm{ml}$ tunicamycin as the best concentrations for inducing ER stress in HepG2 cells while maintaining cell viability during the $24 \mathrm{~h}$ lasting treatment (data not shown). To investigate the response of SND1 promoter activity to these stress inducers, transcriptional activity was measured in HepG2 cells transfected with each of the six 5' deletion fragments SND/1-SND/6 of the isolated promoter [GenBank: EF690304] that were generated and cloned into the Firefly luciferase reporter vector pGL3-Basic. The fragments comprised the promoter regions $-1284,+221 ;-934,+221 ;-622,+221 ;-416,+221$; $-274,+221$ and $-112,+221$. Findings revealed that the activity provided by each luciferase reporter construct increased upon cell exposure to tunicamycin or thapsigargin with rises that oscillated between 50\% and 90\% depending on the construct (Figure 1A). Maximal activation was 


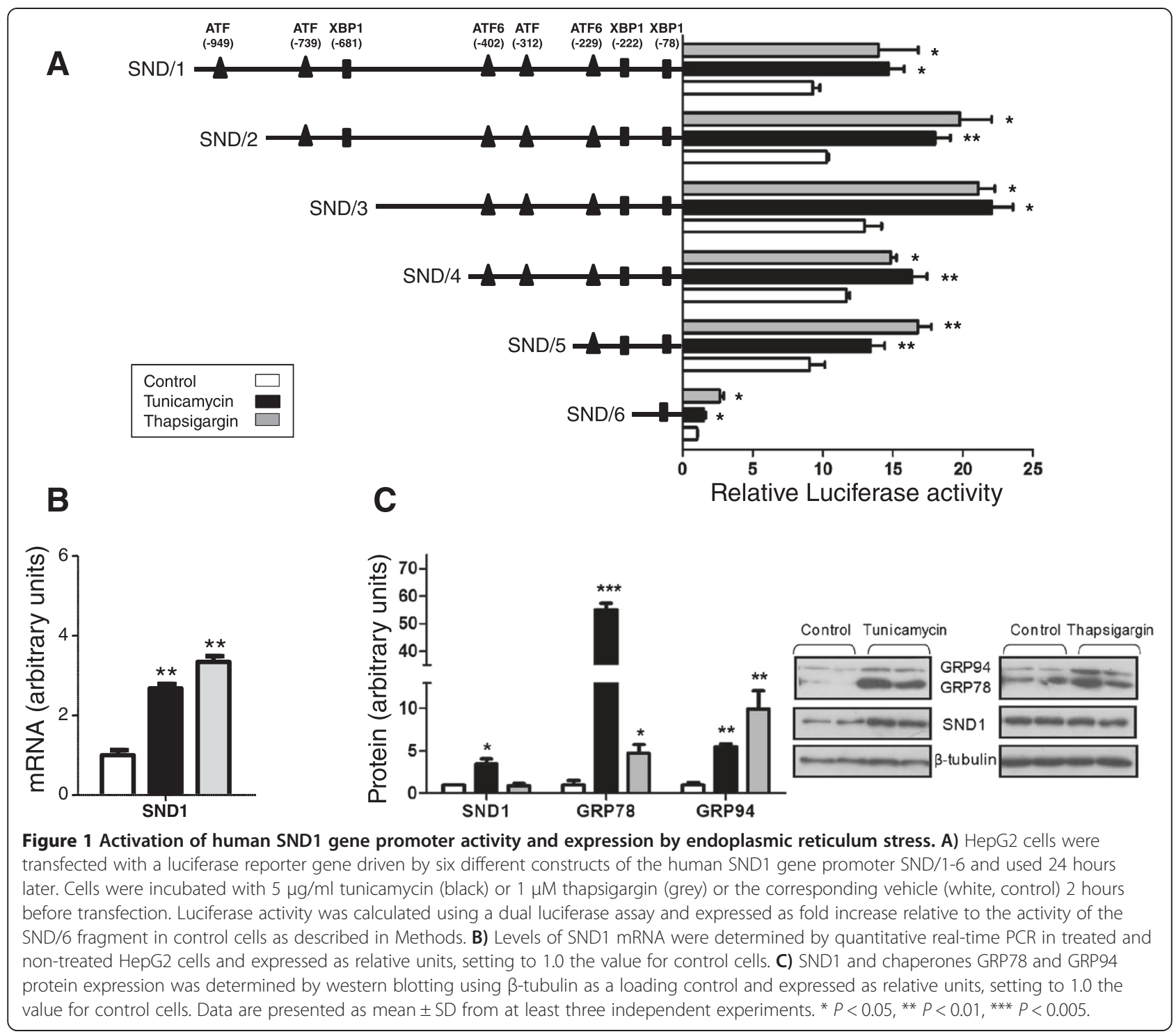

detected in fragment $\mathrm{SND} / 2$, which covers the promoter region -934 upstream the transcription start site.

To examine whether the response of promoter transcriptional activity to ER stressors was paralleled by increases in the expression of SND1 at the level of mRNA and protein, quantitative real-time PCR and western blot analyses were performed in untreated and ER stress inducers-treated cells. Tunicamycin led to a significant 2.7-fold increase in the SND1 mRNA level (Figure 1B) and 3.4-fold increase in the amount of SND1 protein (Figure 1C). However, whereas there was a 3.3-fold increase in the SND1 mRNA level (Figure 1B) in thapsigargin treated cells, no change in SND1 protein levels were observed (Figure 1C). These findings suggest that each specific form of ER stress promotes differential responses on SND1 translational programs.
The well-established rise in protein levels of the ER marker chaperones GRP78 and GRP94 was used as a surrogate index of the induction of ER stress. We found that the protein levels of chaperone GRP78 in tunicamycin- or thapsigargin-treated cells reached values over 55 and 5 times higher than those measured in control cells (Figure 1C). However, the rise in GRP94 protein was higher in thapsigargin- (10 times) than in tunicamycintreated cells (5.5 times) (Figure 1C). These findings suggest that the thapsigargin-induced ER calcium loss of homeostasis [33] and the tunicamycin-induced protein $\mathrm{N}$-glycosylation blockage [32] result in activation of the UPR branches of differential intensities, perhaps through accessory interactions, which might condition the selective induction of gene expression and mRNA translation attenuation and stress granules formation [9,36]. Despite 
this, our findings unambiguously indicate that activation of SND1 gene promoter may be considered one of the processes of cellular adaptability to stressful conditions in HepG2 cells. The finding that SND1 protein is overexpressed in tunicamycin-treated but not in thapsigargintreated cells suggest that the newly transcribed SND1 mRNA may be fully translated when protein glycosylation is impeded but this protein synthesis is inhibited by thapsigargin-induced ER stress. The latter is not an unexpected finding, in view of that calcium in the ER is required for the initiation of protein synthesis in almost all mammalian cell types, and thapsigargin has been demonstrated to sharply and irreversibly suppress amino acid incorporation within HepG2 [11]. It is conceivable that the primary effect of ER stress is to promote SND1 gen activity and that SND1 protein outcomes depend on the nature, intensity and duration of the stress for fine-tuning the cellular response, with SND1 translation arrest operating when certain ER functional circumstances associated to serious degrees of stress are imposed on the cells.

\section{Ectopic expression of ATF6 activates SND1 promoter activity}

To further study the stress-induced activation of the SND1 transcriptional activity, we evaluated the potential role of the transcription factor ATF6 on SND1 promoter activity. ATF6 is initially synthesized and retained by GRP78 in the ER. Upon ER stress, ATF6 is released from GRP78 and deliver to the Golgi apparatus where it undergoes proteolytic processing, and the liberated $\mathrm{N}$-terminal cytosolic fragment ATF6(N) moves then into the nucleus to activate target genes [5]. For that, plasmidmediated ectopic expression of full-length ATF6 was induced in HepG2 cells transfected with each of the six 5' deletion fragments of the SND1 promoter and luciferase activity was measured and compared with that shown by mock transfected cells expressing basal levels of ATF6. We observed that luciferase activity of the SND/3, SND/4, $\mathrm{SND} / 5$ and SND/6 promoter fragments was either unaffected or minimally activated by ATF6 expression (Figure 2A). However, transcriptional activity of the SND/2 fragment increased by $100 \%$ in pCGN-ATF6 transfected HepG2 cells as compared with that measured in mock transfected cells (Figure 2A). Notably, not only the percentage of increase was similar to that caused in the promoter fragments activity by cell exposure to thapsigargin or tunicamycin, but also maximal activation was consistently detected in the $\mathrm{SND} / 2$ construct covering the promoter region $(-934,+221)$ (Figure 2A). Bioinformatic analysis revealed that region $\mathrm{SND} / 2$ contains all the potential motives for ATF6 and XBP1 binding identified by TESS [37], Jaspar [38] and MatInspector [39] tools along the proximal promoter sequence of SND1 gene (GenBank:
EF690304), with the exception of ATF at position -949 (Figure 2B). ATF6 can bind to several cis-acting response elements, namely, ERSE (CCAAT-N9-CCACG), ERSE-II (ATTGG-N1-CCACG), and UPR element (TGACGT GG/A) [8]. ATF6 has been identified as the CCACGbinding protein while the general transcription factor NF-Y constitutively occupies the CCAAT/ATTGG part of ERSE and ERSE-II [8]. In previous studies, we demonstrated that the human SND1 promoter lacks TATA box and contains GC boxes and two inverted CCAAT boxes for the functional binding of Sp1 and NF-Y, respectively [31]. We also demonstrated that NF-Y binding at positions -28 and -61 within the proximal promoter is crucial for the basal transcription of SND1 gene [31]. These NF-Y binding sites are located quite far from the predicted stress response elements to be considered as a part of them according to in silico analysis. However, it has to be considered that the ERSE motives can be recognized by XBP1 and other transcription factors members of the CREB/ATF and EBOX/ATF subfamilies and the basic-region leucine zipper family [8]. Therefore, more work will be required to identify which of the transcription factors, ATF6 or XBP1 or others, and how they act to regulate the activation of SND1 promoter, and to better characterize the branch of the UPR governing the expression of SND1 gene.

The impact of each UPR branch on liver function in pathologic states has been discussed by Malhi and colleagues, who described the existence of a variety of crosstalks between ER stress, inflammatory response and activation of NF- $\mathrm{KB}$ in which ATF6 and XBP1 signaling are involved [40]. We have recently demonstrated that SND1 promoter transcriptional activity increases in response to TNFo-induced inflammatory stress via binding of NF- $\mathrm{kB}$ transcription factor at positions -174 and -116 [31]. Upon such inflammatory stress, a 14-fold induction in the ER chaperone GRP78 has been measured in TNF $\alpha$-treated cells as compared with a negative control (data not shown) supporting the occurrence of perturbations in the ER functional status that could be modulating SND1 gene transcription. Nevertheless, since ATF6 does not substantially affect activity in SND/3-6 and NF- $\mathrm{kB}$ mediates its action through -174 and -116 binding sites, SND1 gene expression activation by these agents might be well orthogonal.

\section{Conclusions}

In conclusion, though the exact function of SND1 in mammals is yet to be revealed, our findings identify ER stress as a previously unappreciated up-regulating factor for SND1 gene expression (see Figure 3 for a graphical representation of major findings). We encounter for the first time a direct response of SND1 gene promoter activity to pharmacological ER stress and the potential 


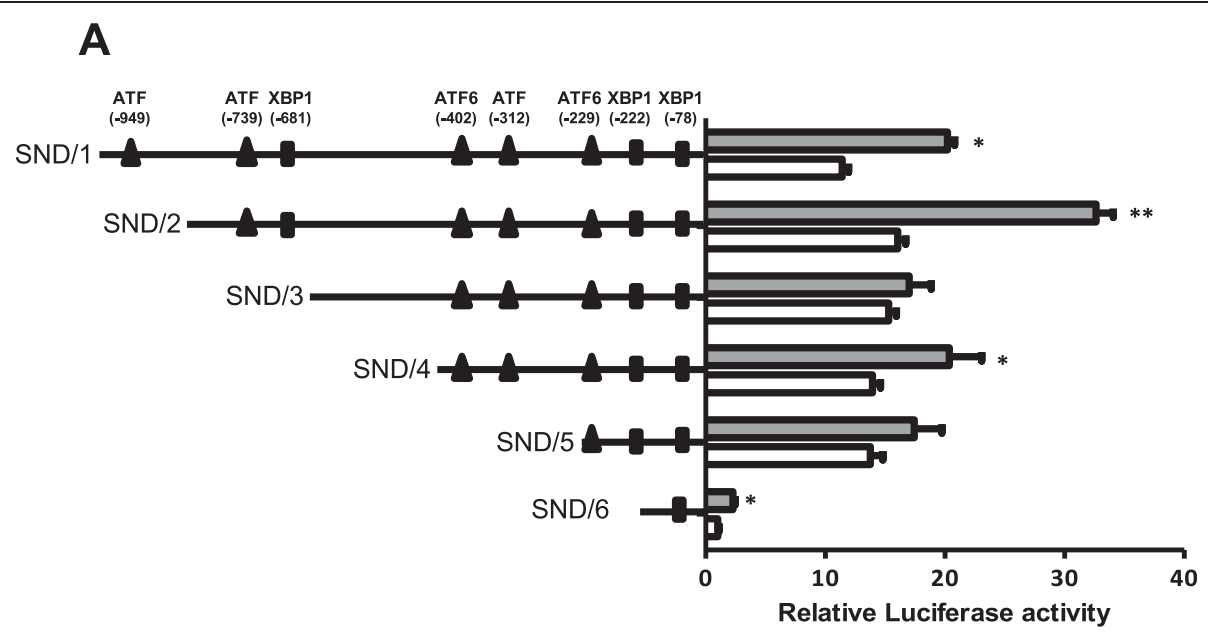

B

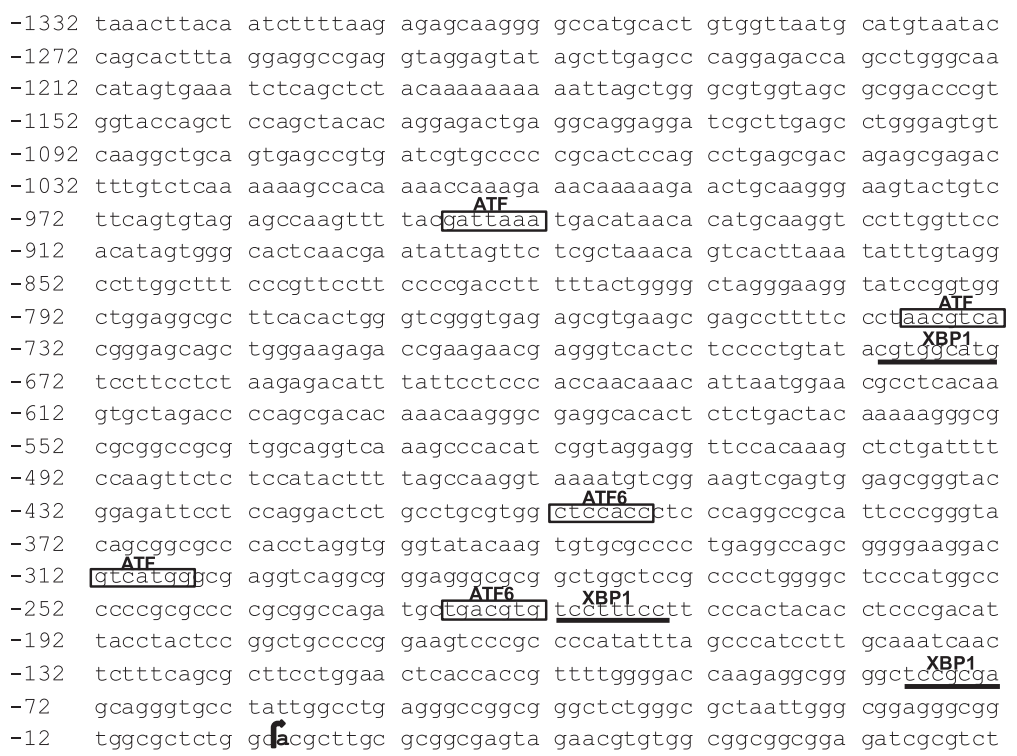

Figure 2 Ectopic expression of ATF6 transcription factor increases SND1 promoter activity. A) HepG2 cells were co-transfected with the SND/1-6 constructs of the human SND1 gene promoter and the ATF6 expression vector and used 24 hours later. Luciferase activity was measured in pCGN-ATF6 transfected cells (grey) and mock transfected cells (white, control) and expressed as fold increase respect to the activity of the SND/6 fragment in control cells. Data are presented as mean \pm SD from at least three independent experiments. ${ }^{*} P<0.05,{ }^{*} P<0.01$. B) Nucleotide sequence of human SND1 gene proximal promoter [GenBank: EF690304]. The transcription start site $(+1)$ is shown in bold and marked by an arrow. Boxes indicate putative binding motives for ATF6 or transcription factors from CREB/ATF or EBOX/ATF subfamilies, and XBP1 binding sites are underlined.

participation of ATF6 in the ER stress-associated transcriptional activation of the human SND1 gene.

\section{Methods}

\section{Cells culture and treatment}

The HepG2 human hepatocellular carcinoma cells (ATCC, Manassas, VA, USA) were maintained under an atmosphere of $5 \% \mathrm{CO}_{2}$ at $37^{\circ} \mathrm{C}$ in EMEM media (ATCC) supplemented with $10 \%(\mathrm{v} / \mathrm{v})$ foetal bovine serum (ATCC), $2 \mathrm{mM}$ L-glutamine, $100 \mathrm{U} / \mathrm{ml}$ penicillin and $100 \mu \mathrm{g} / \mathrm{ml}$ streptomycin (Sigma-Aldrich, St. Louis, MO, USA). Cells were seeded in 96 -well plates $\left(12 \times 10^{3}\right.$ cells per well $)$ for the reporter assays and in 6-well plates $\left(7 \times 10^{5}\right.$ cells per well) for mRNA and western blot analysis and were grown to $60-80 \%$ confluence. Cells were incubated for 24-26 h with $5 \mu \mathrm{g} / \mathrm{ml}$ tunicamycin or $1 \mu \mathrm{M}$ thapsigargin (Sigma) and the same volume of the corresponding solvent, methanol or ethanol, was added to the control cells.

\section{Transfections and luciferase reporter assay}

Two hours before transfection, cells received tunicamycin, thapsigargin or the same volume of the corresponding 


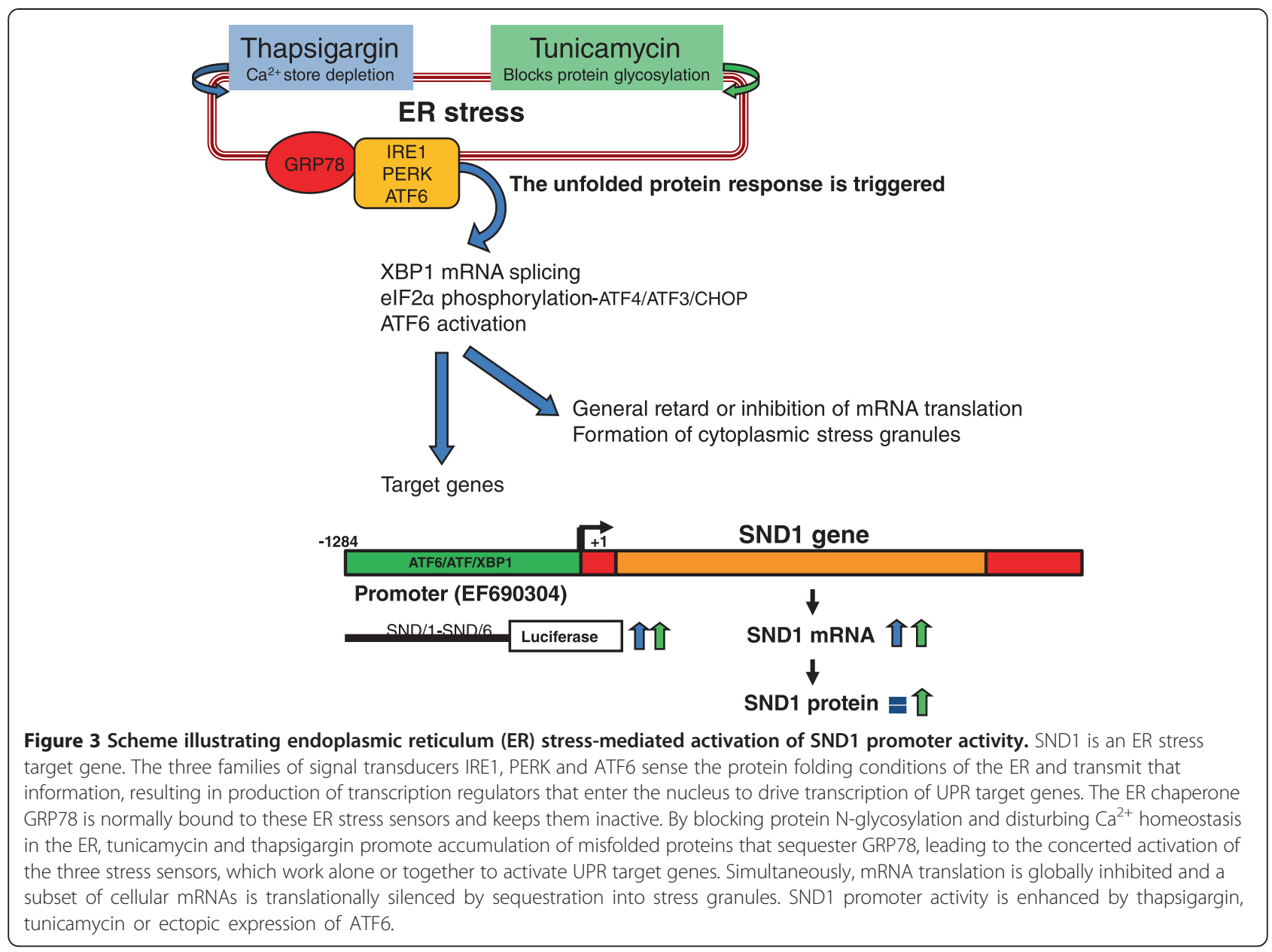

vehicle. Then, cells were transfected using X-tremeGENE 9 transfection reagent (Roche Applied Science, Mannheim, Germany) and received $0.1 \mu \mathrm{g}$ of the appropriate SND1 promoter reporter vector and $0.1 \mu \mathrm{g}$ of Renilla luciferase pRL-TK (Promega, Madison, WI, USA) as internal control for transfection efficiency. We used six 5' deletion fragments SND/1-SND/6 comprising the SND1 promoter regions $-1284,+221 ;-934,+221 ;-622,+221 ;-416$, $+221 ;-274,+221$ and $-112,+221$ cloned into the Firefly luciferase reporter vector pGL3-Basic (Promega) as described previously [31]. When indicated, cells were additionally cotransfected with $0.1 \mu \mathrm{g}$ of the expression plasmid pCGN-ATF6 (Addgene, Cambridge, MA, USA). Mock transfections with the corresponding empty vector were carried out in all cases. After $24 \mathrm{~h}$, cells were lysated and luciferase activity measured using the Dual-Luciferase Reporter Assay System (Promega) in a Synergy ${ }^{\mathrm{Tm}}$ HT Multi- Detection Microplate Reader (BioTek Instruments Inc, Winooski, VT, USA). Firefly luciferase activity from promoter constructs was normalized to Renilla luciferase activity. Assays were performed in triplicate and luciferase values were expressed as relative luminescence units, setting to 1.0 the value for SND/6 luciferase activity.

RNA extraction and quantitative real-time PCR analysis Total RNA was extracted from HepG2 cells twenty four hours after tunicamycin or thapsigargin treatment using TRIzol reagent (Invitrogene Life Technologies, Barcelona, Spain) according to the manufacturer's instructions. First strand cDNA was synthesized from $1 \mu \mathrm{g}$ RNA (NanoDrop ND-1000 spectrophotometer, NanoDrop Technologies, Wilmington, DE) using the SuperScript III system (Invitrogen) and PCR analysis was conducted by the SYBR Green (Applied Biosystem, Foster City, CA, USA) method. Data are expressed as relative expression level and are calculated from the $\mathrm{Ct}$ values applying calibration curves and normalized with $\alpha$-actin, glyceraldehyde 3-phosphate dehydrogenase and TATA box binding protein by using GeNorm 3.5 software [41], as described earlier [42]. The GeneBank accession numbers and primers sequences are: SND1, NM_014390, forward: GTGATCAGATACCGGCAGGATG, reverse: TCTT AATAGCTCTGGCCTCTGCAG; $\alpha$-actin, NM_001101.3, 
forward: GAGCACAGAGCCTCGCCTTTGCC, reverse: CGAGCGCGGCGATATCATCATCC; glyceraldehyde 3phosphate dehydrogenase, NM_002046.3, forward: GGT GAAGCAGGCGTCGGAGG, reverse: GAGGGCAATG CCAGCCCCAG; and TATA box binding protein, NM 003194.3, forward: TTGCAGTGACCCAGCAGCATCAC, reverse: AACCCTTGCGCTGGAACTCGTC.

\section{Immunoblotting}

After $24 \mathrm{~h}$ of tunicamycin or thapsigargin treatment, HepG2 cells were washed and lysated. Briefly, proteins $(10 \mu \mathrm{g})$ from HepG2 cell lysates were resolved by $9 \%$ SDS-PAGE at $170 \mathrm{~V}$ for $1 \mathrm{~h}$ and transferred to polyvinylidene difluoride membranes by semidry transference $(1$ hour at $20 \mathrm{~V})$. SND1 was detected by immunoblot analysis using antibodies anti-rat SNDp102 that recognize human SND1 [17] and a peroxidase-coupled goat antirabbit IgG (Sigma). The level of GRP78 and GRP94 was determined as a marker of ER stress using mouse antiKDEL IgG (Merck Millipore, Germany) that recognizes the peptide sequence SEKDEL of GRP78 and GRP94. For normalization, $\beta$-tubulin was detected by using mouse anti $\beta$-tubulin antibody (Santa Cruz Biotechnology Inc., Dallas, TX, USA) and secondary horse anti-mouse IgG. Protein bands were detected using ECL (GE Healthcare Life Sciences, UK) and quantified by optical densitometry using QuantityOne software (Bio-Rad Laboratories, Hercules, CA, USA), as described previously [43]. After normalization, results were expressed as relative units, setting to 1.0 the value for control cells.

\section{Statistical analysis}

The results are shown as the mean \pm SD of $n$ independent experiments. Statistical significance was assessed using the 2-tailed unpaired Students' $t$-test, and is denoted $* P<0.05$, $* P<0.01$, and $* * P<0.005$.

\section{Abbreviations \\ ATF6: Activating transcription factor 6; CHOP: C/EBP homologous protein; elF2a: Eukaryotic initiation factor 2 alpha; ER: Endoplasmic reticulum; ERSE: ER stress response element; GRP78: Glucose-regulated protein 78; GRP94: Glucose- regulated protein 94; IRE1: Inositol-requiring transmembrane kinase/ endonuclease protein-1; miR: microRNA; PERK: Protein kinase RNA-like ER kinase; SND1: Staphylococcal nuclease and Tudor domain-containing protein 1; UPR: Unfolded protein response; XBP1: X-box binding protein 1.}

\section{Competing interests}

The authors declare that they have no competing interests.

\section{Authors' contributions}

SA carried out the SND1 promoter activity studies and bioinformatic analysis, participated in the interpretation of data and drafted the manuscript. EA participated in the cloning of the promoter $5^{\prime}$ deletion fragments, the transfections and luciferase reporter assays. LE carried out the RNA extraction and participated in the quantitative real-time PCR analysis. SM carried out the cell lysates and participated in the immunoblotting analysis. BO revised critically and edited the manuscript. YC participated in the design of the study and performed the statistical analysis. MJM conceived the study, and participated in its design and coordination, and wrote the manuscript. All authors read and approved the final manuscript.

\section{Acknowledgements}

The authors thank José Antonio López for his technical help with cell cultures. This study was supported by the Basque Government (IT336/10) and the University of the Basque Country (UFI11/20). SA and EA were recipients of a grant for the specialization of doctor researchers and a postdoctoral contract, respectively, from the University of the Basque Country.

Received: 6 November 2014 Accepted: 26 November 2014

Published online: 11 December 2014

\section{References}

1. Ron D, Walter P: Signal integration in the endoplasmic reticulum unfolded protein response. Nat Rev Mol Cell Biol 2007, 8:519-529.

2. Mori K: Tripartite management of unfolded proteins in the endoplasmic reticulum. Cell 2000, 101:451-454

3. Malhotra JD, Kaufman RJ: The endoplasmic reticulum and the unfolded protein response. Semin Cell Dev Biol 2007, 18:716-731.

4. Dufey E, Sepulveda D, Rojas-Rivera D, Hetz C: Cellular Mechanisms of Endoplasmic Reticulum Stress Signaling in Health and Disease. 1. An overview. Am J Physiol Cell Physiol 2014, 307:C582-C594.

5. Walter $P$, Ron D: The unfolded protein response: from stress pathway to homeostatic regulation. Science 2011, 334:1081-1086.

6. Shen J, Chen X, Hendershot L, Prywes R: ER stress regulation of ATF6 localization by dissociation of BiP/GRP78 binding and unmasking of Golgi localization signals. Dev Cell 2002, 3:99-111.

7. Shoulders MD, Ryno LM, Genereux JC, Moresco JJ, Tu PG, Wu C, Yates JR 3rd, Su Al, Kelly JW, Wiseman RL: Stress-independent activation of XBP1s and/or ATF6 reveals three functionally diverse ER proteostasis environments. Cell Rep 2013, 3:1279-1292.

8. Yamamoto K, Yoshida H, Kokame K, Kaufman RJ, Mori K: Differential contributions of ATF6 and XBP1 to the activation of endoplasmic reticulum stress-responsive cis-acting elements ERSE, UPRE and ERSE-II. J Biochem 2004, 136:343-350.

9. Rutkowski DT, Hegde RS: Regulation of basal cellular physiology by the homeostatic unfolded protein response. J Cell Biol 2010, 189:783-794.

10. Kedersha N, Stoecklin G, Ayodele M, Yacono P, Lykke-Andersen J, Fritzler MJ, Scheuner D, Kaufman RJ, Golan DE, Anderson P: Stress granules and processing bodies are dynamically linked sites of mRNP remodeling. J Cell Biol 2005, 169:871-884.

11. Brostrom MA, Brostrom CO: Calcium dynamics and endoplasmic reticular function in the regulation of protein synthesis: implications for cell growth and adaptability. Cell Calcium 2003, 34:345-363.

12. Tong X, Drapkin R, Yalamanchili R, Mosialos G, Kieff E: The Epstein-Barr virus nuclear protein 2 acidic domain forms a complex with a novel cellular coactivator that can interact with TFIIE. Mol Cell Biol 1995, 15:4735-4744.

13. Broadhurst MK, Wheeler $\Pi$ : The $p 100$ coactivator is present in the nuclei of mammary epithelial cells and its abundance is increased in response to prolactin in culture and in mammary tissue during lactation. J Endocrinol 2001, 171:329-337.

14. Blanco MA, Aleckovic M, Hua Y, Li T, Wei Y, Xu Z, Cristea IM, Kang Y: Identification of staphylococcal nuclease domain-containing 1 (SND1) as a Metadherin-interacting protein with metastasis-promoting functions. J Biol Chem 2011, 286:19982-19992.

15. Duan Z, Zhao X, Fu X, Su C, Xin L, Saarikettu J, Yang X, Yao Z, Silvennoinen O, Wei M, Yang J: Tudor-SN, a novel coactivator of peroxisome proliferatoractivated receptor gamma protein, is essential for adipogenesis. $J$ Biol Chem 2014, 289:8364-8374.

16. Garcia-Arcos I, Rueda Y, Gonzalez-Kother P, Palacios L, Ochoa B, Fresnedo O: Association of SND1 protein to low density lipid droplets in liver steatosis. J Physiol Biochem 2010, 66:73-83.

17. Palacios L, Ochoa B, Gomez Lechón MJ, Castell JV, Fresnedo O: Overexpression of SND p102, a rat homologue of p100 coactivator, promotes the secretion of lipoprotein phospholipids in primary hepatocytes. Biochimica et Biophysica Acta (BBA) - Mole Cell Biol Lipids 2006, 1761:698-708.

18. Gao X, Ge L, Shao J, Su C, Zhao H, Saarikettu J, Yao X, Yao Z, Silvennoinen O, Yang J: Tudor-SN interacts with and co-localizes with G3BP in stress granules under stress conditions. FEBS Lett 2010, 584:3525-3532.

19. Yang J, Valineva T, Hong J, Bu T, Yao Z, Jensen ON, Frilander MJ, Silvennoinen O: Transcriptional co-activator protein p100 interacts 
with snRNP proteins and facilitates the assembly of the spliceosome. Nucleic Acids Res 2007, 35:4485-4494.

20. Scadden AD: The RISC subunit Tudor-SN binds to hyper-edited doublestranded RNA and promotes its cleavage. Nat Struct Mol Biol 2005, 12:489-496

21. Cappellari M, Bielli P, Paronetto MP, Ciccosanti F, Fimia GM, Saarikettu J, Silvennoinen $\mathrm{O}$, Sette $\mathrm{C}$ : The transcriptional co-activator SND1 is a novel regulator of alternative splicing in prostate cancer cells. Oncogene 2014, 33:3794-3802.

22. Scadden AD: Inosine-containing dsRNA binds a stress-granule-like complex and downregulates gene expression in trans. Mol Cell 2007, 28:491-500.

23. Weissbach R, Scadden AD: Tudor-SN and ADAR1 are components of cytoplasmic stress granules. RNA 2012, 18:462-471.

24. Gao X, Shi X, Fu X, Ge L, Zhang Y, Su C, Yang X, Silvennoinen O, Yao Z, He J, Wei M, Yang J: Human Tudor staphylococcal nuclease (Tudor-SN) protein modulates the kinetics of AGTR1-3'UTR granule formation. FEBS Lett 2014, 588:2154-2161.

25. Heinrich EM, Wagner J, Kruger M, John D, Uchida S, Weigand JE, Suess B, Dimmeler S: Regulation of miR-17-92a cluster processing by the microRNA binding protein SND1. FEBS Lett 2013, 587:2405-2411.

26. Tsuchiya N, Ochiai M, Nakashima K, Ubagai T, Sugimura T, Nakagama H: SND1, a component of RNA-induced silencing complex, is up-regulated in human colon cancers and implicated in early stage colon carcinogenesis. Cancer Res 2007, 67:9568-9576.

27. Kuruma H, Kamata Y, Takahashi H, Igarashi K, Kimura T, Miki K, Miki J, Sasaki H, Hayashi N, Egawa S: Staphylococcal nuclease domaincontaining protein 1 as a potential tissue marker for prostate cancer. Am J Pathol 2009, 174:2044-2050.

28. Ho J, Kong JW, Choong LY, Loh MC, Toy W, Chong PK, Wong CH, Wong CY, Shah N, Lim YP: Novel breast cancer metastasis-associated proteins. J Proteome Res 2009, 8:583-594.

29. Yoo BK, Santhekadur PK, Gredler R, Chen D, Emdad L, Bhutia S, Pannell L, Fisher PB, Sarkar D: Increased RNA-induced silencing complex (RISC) activity contributes to hepatocellular carcinoma. Hepatology 2011, 53:1538-1548.

30. Santhekadur PK, Das SK, Gredler R, Chen D, Srivastava J, Robertson C, Baldwin AS Jr, Fisher PB, Sarkar D: Multifunction protein Staphylococcal Nuclease Domain containing 1 (SND1) promotes tumor angiogenesis in human hepatocellular carcinoma through novel pathway that involves nuclear factor kappa B and miR-221. J Biol Chem 2012, 287:13952-13958.

31. Armengol S, Arretxe E, Rodriguez L, Ochoa B, Chico Y, Martinez MJ: NF-kB, Sp1 and NF-Y as transcriptional regulators of human SND1 gene. Biochimie 2013, 95:735-742.

32. King IA, Tabiowo A: Effect of tunicamycin on epidermal glycoprotein and glycosaminoglycan synthesis in vitro. Biochem J 1981, 198:331-338.

33. Sagara Y, Inesi G: Inhibition of the sarcoplasmic reticulum Ca2+ transport ATPase by thapsigargin at subnanomolar concentrations. J Biol Chem 1991, 266:13503-13506.

34. Wu J, Rutkowski DT, Dubois M, Swathirajan J, Saunders T, Wang J, Song B, Yau GD, Kaufman RJ: ATF6alpha optimizes long-term endoplasmic reticulum function to protect cells from chronic stress. Dev Cell 2007, 13:351-364

35. Fang DL, Wan Y, Shen W, Cao J, Sun ZX, Yu HH, Zhang Q, Cheng WH, Chen J, Ning B: Endoplasmic reticulum stress leads to lipid accumulation through upregulation of SREBP-1C in normal hepatic and hepatoma cells. Mol Cell Biochem 2013, 381:127-137.

36. Kamiya $\mathrm{T}$, Hara $\mathrm{H}$, Adachi $\mathrm{T}$ : Effect of endoplasmic reticulum (ER) stress inducer thapsigargin on the expression of extracellular-superoxide dismutase in mouse 3 T3-L1 adipocytes. J Clin Biochem Nutr 2013, 52:101-105.

37. Schug J: Using TESS to predict transcription factor binding sites in DNA sequence. Curr Protoc Bioinformatics 2008, Chapter 2: Unit.

38. Sandelin A, Alkema W, Engstrom P, Wasserman WW, Lenhard B: JASPAR: an open-access database for eukaryotic transcription factor binding profiles. Nucleic Acids Res 2004, 32:D91-D94.

39. Cartharius K, Frech K, Grote K, Klocke B, Haltmeier M, Klingenhoff A, Frisch M, Bayerlein $M$, Werner T: Matlnspector and beyond: promoter analysis based on transcription factor binding sites. Bioinformatics 2005, 21:2933-2942.

40. Malhi H, Kaufman RJ: Endoplasmic reticulum stress in liver disease. J Hepatol 2011, 54:795-809.
41. Vandesompele J, De PK, Pattyn F, Poppe B, Van RN, De PA, Speleman F: Accurate normalization of real-time quantitative RT-PCR data by geometric averaging of multiple internal control genes. Genome Biol 2002, 3: RESEARCHO034

42. Delgado I, Fresnedo O, Iglesias A, Rueda Y, Syn WK, Zubiaga AM, Ochoa B: A role for transcription factor E2F2 in hepatocyte proliferation and timely liver regeneration. Am J Physiol Gastrointest Liver Physiol 2011, 301:G20-G31.

43. Aspichueta P, Perez S, Ochoa B, Fresnedo O: Endotoxin promotes preferential periportal upregulation of VLDL secretion in the rat liver. J Lipid Res 2005, 46:1017-1026.

doi:10.1186/s12858-014-0025-2

Cite this article as: Armengol et al:: The promoter of cell growth- and RNA protection-associated SND1 gene is activated by endoplasmic reticulum stress in human hepatoma cells. BMC Biochemistry 2014 15:25.

\section{Submit your next manuscript to BioMed Central and take full advantage of:}

- Convenient online submission

- Thorough peer review

- No space constraints or color figure charges

- Immediate publication on acceptance

- Inclusion in PubMed, CAS, Scopus and Google Scholar

- Research which is freely available for redistribution
C Biomed Central 